
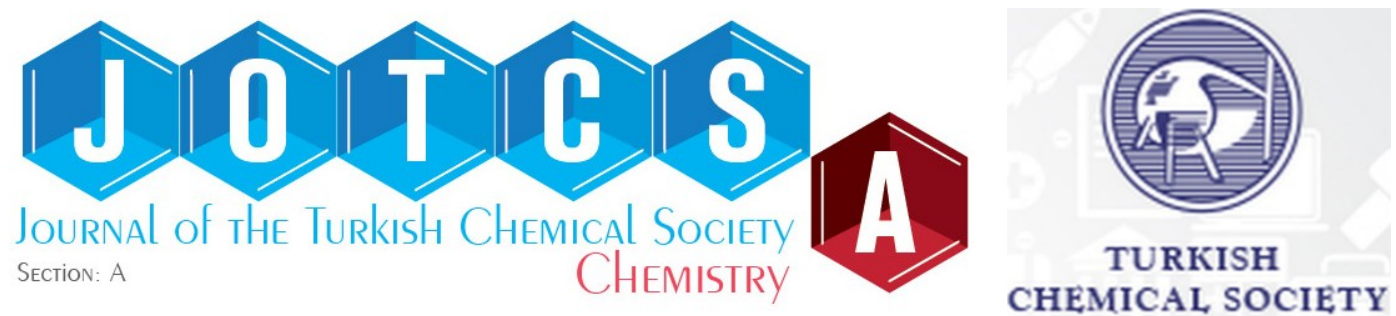

\title{
The Effects of Blending Ratio of Poly(lactic acid)/POSS Cored Star Poly( $\varepsilon$-caprolactone) Biopolymers
}

\author{
M. DANDAN DOĞANCI $\triangle$ iD \\ Department of Chemistry and Chemical Processing Tech., Kocaeli University, Kocaeli, Turkey
}

\begin{abstract}
A_{8}$-type eight-arm star-shaped poly( $\varepsilon$-caprolactone) (PCL) polymers with polyhedral oligomeric silsesquioxane (POSS) (SP) core having different molecular weight with different chain lengths ( $n=10,20$, 30 , and 50 repeating units) were synthesized via arm-first approach by a combination of ringopening polymerization (ROP) and "click" chemistry reactions. The obtained polymers were then meltblended with neat poly(lactic acid) (PLA) to improve some of the properties like the toughness of PLA. These blends were prepared depending on the blend ratio (95/5 and $80 / 20 \mathrm{wt} \%$ ) via utilizing laboratory-scale twin-screw mini extruder to examine morphological, thermal, and mechanical properties of PLA/SP composite as a function of SP and blending ratio. Also, the PLA/SP composites containing a blend ratio of $90 / 10 \mathrm{wt} \%$, which were prepared in the previous study, was used to compare with other composite having different blend ratio. The incorporation of SP polymers improved some of the mechanical properties of PLA. It was verified that SP20 $(n=20)$ is the most proper SP-type for enhancing the mechanical behavior of PLA at a blending ratio of $90 / 10$. Also, 1,4-phenylene diisocyanate (PDI), which was used as a commercial compatibilizer, was incorporated to blends at a fixed amount $(\% 1)$. It is concluded that the incorporation of SP polymers into PLA matrix decreased the tensile modulus with increasing blending ratio and increased the elongation at break values in the presence of PDI.
\end{abstract}

Keywords: Blending ratio, Star shaped polymers, PLA, PCL, POSS.

Submitted: June 12, 2020. Accepted: July 06, 2020.

Cite this: DANDAN DOĞANCI M. The Effects of Blending Ratio of Poly(lactic acid)/POSS Cored Star Poly( $\varepsilon$ caprolactone) Biopolymers. JOTCSA. 2020;7(3):649-60.

DOI: https://doi.org/10.18596/jotcsa.752190.

*Corresponding author. E-mail: merve.doganci@kocaeli.edu.tr.

\section{INTRODUCTION}

Poly(lactic acid) (PLA) and poly( $\varepsilon$-caprolactone) $(P C L)$ are two crucial biodegradable aliphatic polyesters that are commonly used together, although the two polymers are incompatible. These polymers have quite different features, such as the fact that PLA is fragile, and PCL is ductile. The mechanical properties of PLA generally enhanced by adding PCL polymers to PLA matrix with different methods such as blending, synthesizing copolymers, etc. (1-3). The miscibility, viscoelastic, thermodynamic, and mechanical behaviors of the PLA/PCL blend system have been extensively studied. Broz and coworkers produced a series of PLA/PCL blends via different mass fractions to examine the mechanical and structural characteristics of the blends. They concluded that these two biodegradable polymers, PLA and PCL, are immiscible, and there occurs some adhesion between two polymers when the PCL phase is dominant (4). Simoes et al. also reported some degree of adhesion between PLA and PCL biodegradable polymers and determined that $\mathrm{PCL}$ acted like a plasticizer for PLA by improving the ductility, flexibility, and mechanical properties of PLA (5). Rao and coworkers studied with these two polymers and examined $80 / 20 \%$ PLA/PCL blend exhibited the highest impact strength and elongation at break among the various blend proportions $(6,7)$. Vainio et al. synthesized $\varepsilon$ caprolactone and L-lactide ( $\varepsilon-\mathrm{CL} / \mathrm{L}-\mathrm{LA}$ ) copolymers with different compositions (40/60, 60/40, and 
$80 / 20$ ) and found that tensile properties were much higher than pure polymers (8).

Recently, multiarmed star-shaped polymers have attracted increasing attention due to their excellent properties and three-dimensional structures. The star-shaped polymers are generally characterized by lower glass transition temperature $\left(T_{g}\right)$ and melt viscosity. They are more compact and less crystalline in comparison to linear counterparts of the same molecular weights $(3,9)$. The starbranched block and random copolymers of LA and $\varepsilon$ $\mathrm{CL}$ are a candidate for enhancing the toughness of PLA. Several studies in the literature prepared blends of PLA with synthesized star-shaped polymers $(3,9,10)$. Deokar et al. prepared three, four, and six-armed random and block star polymers of PCL-PLA and blended with PLA. They concluded that maximum enhancement in elongation and toughness was observed with sixarmed block copolymers (3). Li et al. produced a series of star-shaped PCLs with different molecular weights and mixed with PLA to obtain blended fiber membranes via electrospinning technique. They examined the influence of multiple-armed structure on the mechanics and thermodynamics feature of the electrospun fiber membranes (9). Qin et al. prepared blends of PLA and star-shaped $\operatorname{poly}(\varepsilon-$ caprolactone-co-L-lactide) (s-PCLA) at varying compositions and concluded that PLA/s-PCLA blends showed limited miscibility and better elongation at break (10).

Polyhedral oligomeric silsesquioxane (POSS) are new generation nanofillers with a general formula of $\left(\mathrm{RSiO}_{1.5}\right)_{\mathrm{n}}$. It is generally used to improve the mechanical and thermal properties of PCL, PLA, and its blends by physical blending or chemical reactions (11-19). It can also be utilized as a polymerizable monomer or initiator to synthesize star-shaped polymers. Sun and He synthesized (octaPOSS)initiated poly ( $\varepsilon$-caprolactone-co-lactide) (PCLLA) as rubbery core and mixed it with commercial poly( $L-$ lactide) (PLLA) by solution blending for toughening. The obtained biodegradable nanocomposites showed higher elongation at break to that of pure PLA (20). Pan et al. synthesized star POSS-(PLLA) $(x=6,9$, 11 , and 12) polymers and blended with PLA. The effects of molecular geometry and arm length of star polymers on crystallinity and properties of PLA were investigated. They concluded that the highest crystallinity was observed with 12-armed POSS$(\text { PLLA })_{12}$ blends (12). Liu et al. synthesized POSS$(P L L A)_{8}$ and blended this polymer with PLA via the solvent casting method. The interfacial interactions were considerably developed, and a good increase was observed in toughness and mechanical properties (11). In the previous study, star-shaped PCLs (SPS) with POSS core were synthesized and prepared melt-blend with commercial PLA by utilizing mini twin-screw extruder to increase the toughness properties of PLA. The mechanical, thermal, and morphological behaviors of these blends were examined as a function of star-shaped polymer type possessing different molecular weight depending on different chain lengths at constant PLA/SP ratio. It was found that increasing the toughness of commercial PLA thanks to ductile PCL having relatively low $T_{g}$. Besides, the addition of SP polymers into commercial PLA improved morphological and some mechanical properties (like elongation at break and izod impact strength) (19).

In this work, eight-armed POSS cored star-shaped $\mathrm{PCL}$ (POSS- $\left.(\mathrm{PCL})_{8}, \mathrm{SP}\right)$ polymers having various chain lengths $(n=10,20,30$, and 50) were produced and compounded with commercial PLA with different blending ratios (PLA/SP, 95/5 and $80 / 20$ ). In a previous study, the effects of $90 / 10$ blended PLA/SP polymers were discussed (19). Here, these blends having different blending ratios were compared with neat PLA. Also, the PDI, a commercial compatibilizer, was added to blends at a constant amount of $1 \mathrm{wt} \%$, and their effects on PLA's properties and phase morphology were investigated.

\section{EXPERIMENTAL SECTION}

\section{Materials and Method}

All materials and polymers used in this work, and the preparation of PLA/SP blends, have been described in the previously published paper (19). The commercial PLA (PLI005) was procured from NaturePlast, having a molecular weight 71,900 $\mathrm{g} / \mathrm{mol}$ (determined by GPC) and used after drying at $65{ }^{\circ} \mathrm{C}$ under vacuum overnight. A commercial compatibilizer, 1,4-phenylene diisocyanate (PDI) was purchased from Sigma Aldrich. The chlorine functionalized POSS (POSS- $\left.(\mathrm{Cl})_{8}\right)_{\text {, }}$ azide functionalized POSS (POSS- $\left.\left(\mathrm{N}_{3}\right)_{8}\right)$ and POSS cored star-shaped $P C L$ (SP) polymers having various chain lengths $(n=10,20,30$ and 50) were synthesized according to a method in the previous work, too. Subsequently, synthesized polymers were meltblended with PLA with a blending ratio of 95/5 and $80 / 20$ wt\%. Some of the results belong to blends of $90 / 10$ wt\% ratio were extracted from the previous study (19) to make comparisons of blend ratios.

The morphology of blends was searched via scanning electron microscopy (FEI- QUANTA FEG 250- Field Emission Scanning Electron Microscope (FE-SEM)). Instron universal testing machine (Model 3345) and Zwick/Roell impact testing machine were used for tensile tests and impact strength analysis respectively to determine mechanical characters of the blends. Melting temperature and crystallization behaviors of blends were analyzed via DSC by Mettler Toledo DSC-1 Star Model calorimeter with a $10{ }^{\circ} \mathrm{C} / \mathrm{min}$ scan rate, from room temperature to 250 ${ }^{\circ} \mathrm{C}$ with $\mathrm{N}_{2}$ atmosphere. Thermal decomposition properties were determined via Mettler Toledo TGA 1 Star System TGA between 25 and $650{ }^{\circ} \mathrm{C}$ at a 
heating rate of $15{ }^{\circ} \mathrm{C} \min ^{-1}$ under an argon atmosphere.

\section{Synthesis of Alkyne Functional Linear PCL Polymers (Alkyne PCL)}

Alkyne-PCL polymers with different repeating units $(n=10,20,30$, and 50$)$ to prepare different chain lengths were again synthesized according to the previous procedure described elsewhere (19). ROP successfully helped prepare these polymers by utilizing an initiator (propargyl alcohol) and a catalyst (tin octanoate, $\mathrm{Sn}(\mathrm{Oct})_{2}$ ).

Synthesis of $A_{8}$-type homo-arm POSS cored star-shaped PCLs (POSS-(PCL) 8 )

POSS- $\mathrm{N}_{3}$, as a multifunctional core, was prepared according to the previously published literature procedures (19). A A $_{8}$-type homo-arm POSS cored star-shaped PCLs were successfully synthesized via copper(I)-catalyzed click reaction using $\operatorname{POSS}\left(\mathrm{N}_{3}\right)_{8}$ as clickable azide and alkyne-PCL having three different chain lengths under ambient conditions with high yield.

Blend preparation with micro- extruder and injection

A laboratory-scale twin-screw mini extruder (max. feeding volume $15 \mathrm{~mL}$ ) was utilized to prepare PLA/ SP blends (Xplore Instruments MC 15, The Netherlands). The blend ratios and contents wt\% of PLA/SP and PLA/PDI/SP blends are given in Table 1. The mixing of two polymers was performed at 190 ${ }^{\circ} \mathrm{C}$ and 2 min mixing time, the screw speed of the extruder was $100 \mathrm{rpm}$, following injection molding machine (Xplore $12 \mathrm{~mL}$ ) was used to produce mechanical test specimens. The temperatures for mold and melt were $25^{\circ} \mathrm{C}$ and $190^{\circ} \mathrm{C}$. The PDI was used as a commercial compatibilizer and added a constant amount as $1.0 \mathrm{wt} \%$.

Table 1: The blend ratios and contents wt\% of PLA/SP and PLA/PDI/SP blends.

\begin{tabular}{|c|c|c|c|c|}
\hline \multicolumn{2}{|c|}{ Blend ratio } & $\begin{array}{c}\text { PLA } \\
\text { (wt\%) }\end{array}$ & $\begin{array}{c}\text { SP } \\
\text { (wt\%) }\end{array}$ & $\begin{array}{c}\text { PDI } \\
\text { (wt\%) }\end{array}$ \\
\hline \multicolumn{2}{|r|}{ Pure PLA } & 100.0 & - & - \\
\hline \multicolumn{2}{|r|}{ PLA/PDI } & 99.0 & - & 1.0 \\
\hline \multirow{2}{*}{$95 / 5$} & PLA/SP & 95.0 & 5.0 & - \\
\hline & PLA/PDI/SP & 94.05 & 4.95 & 1.0 \\
\hline \multirow{2}{*}{$80 / 20$} & PLA/SP & 80.0 & 20.0 & - \\
\hline & PLA/PDI/SP & 79.2 & 19.8 & 1.0 \\
\hline
\end{tabular}

\section{RESULTS AND DISCUSSION}

\section{Vertical Force (VF) Measurements}

The vertical force is generally used to get information about melt viscosity of the polymers or blends. It is measured while the molten polymer was pumped through the recirculation channel or die during the extrusion process. In this study, PLA and SP polymers were compounded in the lab-scale extruder machine at the rates of $100 / 0,95 / 5,90 / 10$ and $80 / 20 \% \mathrm{w} / \mathrm{w}$ and the vertical force $(\mathrm{N})$ values, which were recorded during the blending process, were used to compare melt viscosities of blends. The studies were carried out at $190{ }^{\circ} \mathrm{C}$ at $100 \mathrm{rpm}$ mixing speed for 2 minutes of retention time. The changes in vertical force $(\mathrm{N})$ values recorded against time for pure PLA, and PLA/SP and PLA/PDI/SP blends with $95 / 5$ and $80 / 20(\mathrm{w} / \mathrm{w})$ are given in Figure 1. 

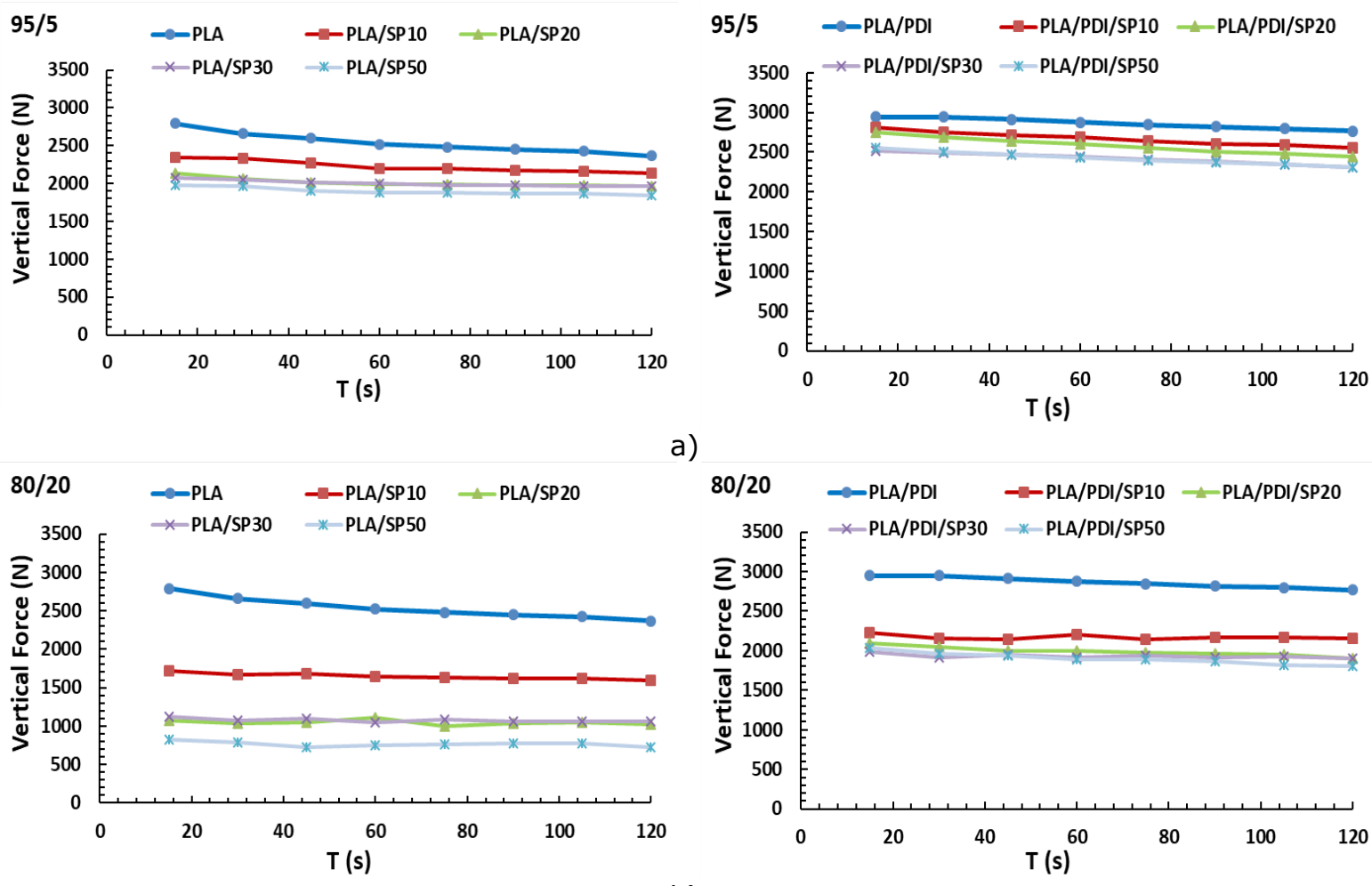

a)

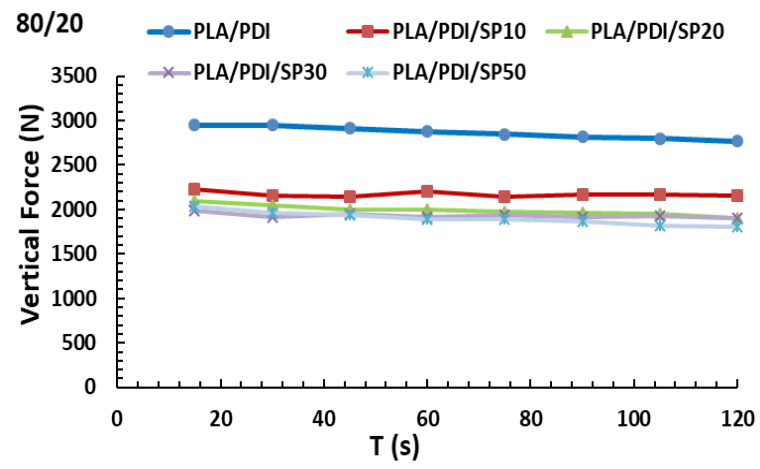

b)

Figure 1: The variation of vertical force of PLA/SP and PLA/PDI/SP blends at a rate of a) $95 / 5$ and b) $80 / 20(w / w)$.

As well as being a fragile polymer, PLA is a problematic polymer to process due to its high melting point and high viscosity at processing temperatures. The melt viscosity value of pure PLA is higher than PLA/SP blends for any time, as seen in Figure 1. When SPs were added to the PLA, it caused a decrease in melt viscosity due to the plasticizing effect of PCL. Also, the star polymers generally have a smaller solution and melt viscosity in comparison to linear ones and cause more natural blending with a reduction in vertical force values (3, 10, 21). However, POSS molecules in the star polymer act as an internal slip agent, helping to reduce the melt viscosity of the mixtures $(13,19$, $22,23)$. As can be seen from Figure 1 , the melt viscosity is higher in the mixtures of $95 / 5$ compared to the mixtures of $90 / 10$ and $80 / 20$, and a good decrease was detected proportional to the blending ratio as the amount of SPs was more significant in $80 / 20$ blends (19). The melt viscosity decreased with the increase of arm length of the SPs, and this is more noticeable in $80 / 20$ blends, as seen in Figure 1b. In PLA/PDI/SP blends, PDI behaves as a compatibilizer between two polymers and causes chain extension reactions between end groups of SPs and PLA. The chain extension mechanism has been described in detail in a previous study (19). The occurrence of PLA-CO-SP structures in the blends results in in-situ compatibilization and causes a slight increment in the melt viscosity of the triplet blends when compared to binary blends (24-26). In any case, the melt viscosity is higher in the mixtures of $95 / 5,90 / 10$ and $80 / 20$, respectively.

\section{Mechanical Properties of PLA/SP and PLA/PDI/SP Blends}

The mechanical properties of polymer blends are generally among the properties of each component. Besides, the blending ratio, the miscibility and compatibility levels of the mixtures play an essential role in defining the final properties of the mixture. PLA is inherently fragile with very low elongation at break (EAB) and relatively low impact strength (5, $7,19,27,28)$. Since it is a very fragile material, it is generally used by adding plasticizers to improve its mechanical properties and obtain a stricter structure. In this study, SP polymers act as a plasticizer, providing improvements in the mechanical behaviors of PLA. The change in the tensile modulus of PLA/SP and PLA/PDI/SP blends at different blending ratios 95/5, 90/10, and 80/20 are given in Figure $2 a$. It can be seen that there is a significant decrease in the tensile modulus values of star polymer blends with and without PDI compared to neat PLA. The decrease in the tensile modulus of PLA/SP blends was supposed since PCL polymers generally have lower tensile strength and modulus compared to neat PLA. The lower values were generally obtained in $90 / 10$ and $80 / 20$ blend ratios according to $95 / 5$ blends. The inclusion of SP polymers caused a decrement in the tensile modulus of pure PLA rather than linear ones (29). The lowest 
tensile modulus value was found in the PLA/PDI/SP20 blend. It was observed that there was an increase in tensile modulus values in $80 / 20$ blends due to both increasing arm number (hence increasing molecular weight) and increasing SP blend ratio. The significant enhancement in mechanical properties was observed in $E A B$ values of PLA/SP, and PLA/PDI/SP blends in Figure $2 \mathrm{~b}$. The $90 / 10$ blends have the highest $E A B$ showing that the most proper ratio for interaction between PLA and star PCL polymers. In the case of PDI, it is more evident that SP20 polymer has a significant increase in $90 / 10$ blends proving SP20 is the reasonable saturation level of molecular arm length and shows maximum interaction with PLA due to chain extension (19). The blend ratio effect also can be seen in yield strength. The values of $95 / 5$ blends were found to be higher compared to that of pure PLA, however, the lowest value was determined in 90/10 blends in Figure 2c.
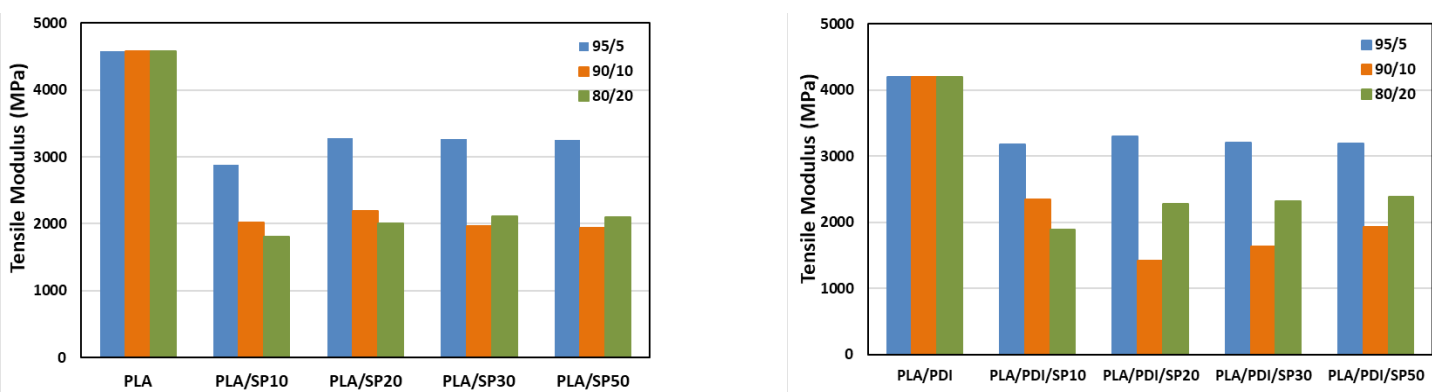

a)
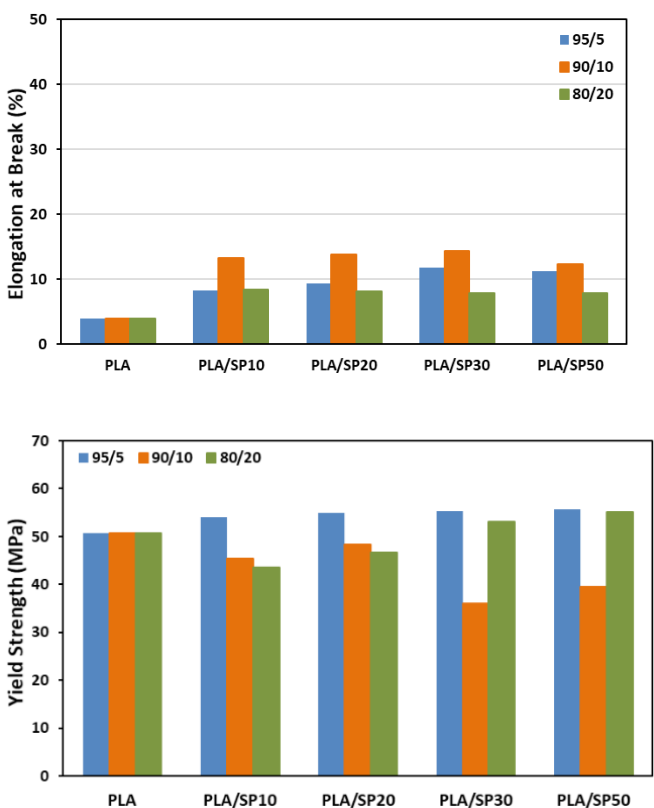

b)

c)

Figure 2: Mechanical properties of PLA/SP and PLA/PDI/SP blends a) tensile modulus, b) elongation at break (\%), c) yield strength at different blending ratios 95/5, 90/10 and 80/20.
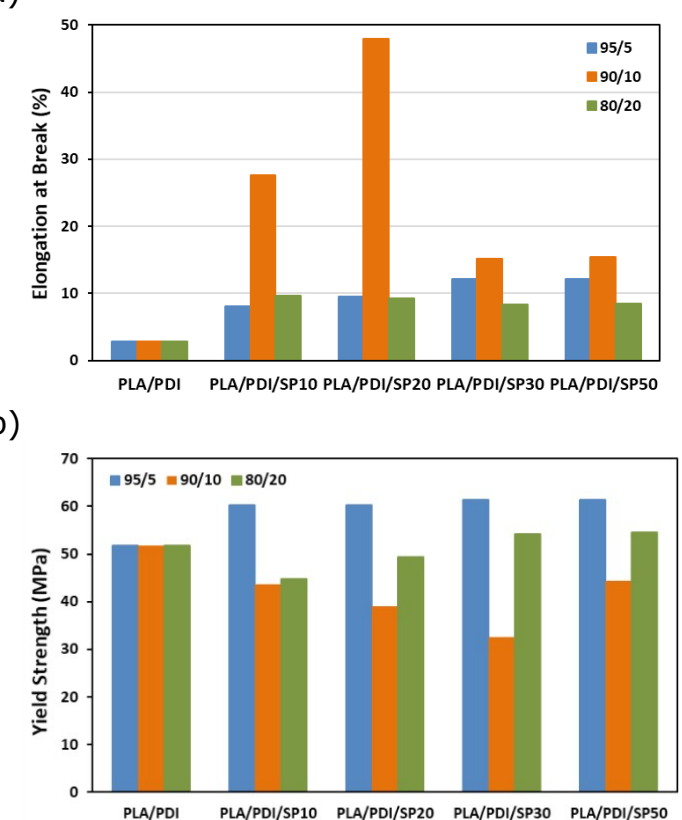

The Izod impact strength values of PLA/SP and PLA/ PDI/SP blends at different blending ratios 95/5, 90/10, and 80/20 were given in Figure 3a. The impact strength of the blends showed an increasing trend in both cases with and without PDI compared to pure PLA. It is concluded that the SPs behaved as an impact modifier, and maximum effect was observed at $90 / 10$ blends in concordance with $E A B$ results. Here again, PLA/PDI/SP20 blends had maximum value proving that SP20 has the most available arm length (or molecular weight) at interaction with PLA in the presence of PDI with the help of chain extension reactions (19). The Shore D Hardness values of blends are given in Figure $3 \mathrm{~b}$. There is a slight decrease in hardness when compared to pure PLA. 90/10 blends have lower values when compared to that of $95 / 5$ and $80 / 20$ blends. 

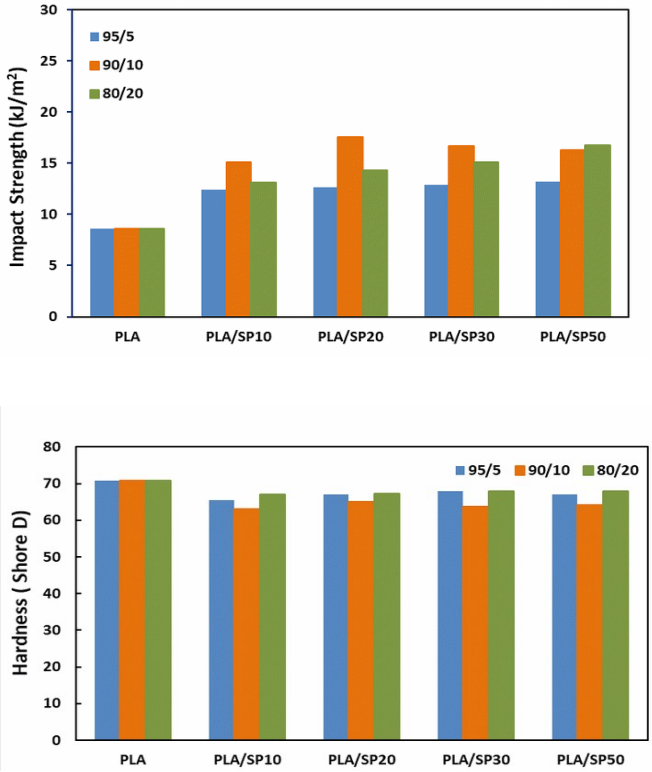

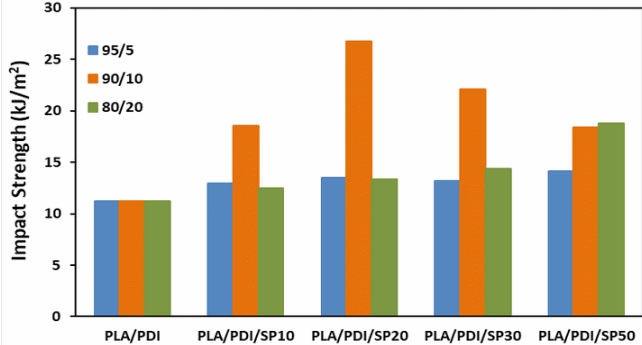

a)

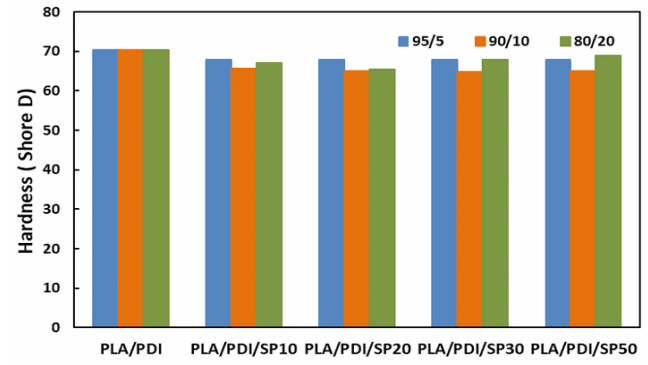

Figure 3: a) The Izod impact strength and b) hardness of PLA/SP and PLA/PDI/SP blend at different blending ratios 95/5, 90/10, and 80/20.

\section{Thermal Properties of PLA/SP and PLA/PDI/SP Blends}

The thermal properties of PLA/SP and PLA/PDI/SP blends at 95/5, and 80/20 blend ratios are given in Table 2, and DSC thermograms are depicted in Figure 4. A good decrease was observed in glass transition temperature $\left(T_{g}\right)$ with the change of blend ratio from $95 / 5$ to $80 / 20$, and the lowest $T_{g}$ value was found as $47{ }^{\circ} \mathrm{C}$ for the $80 / 20$ blends. The decrease in $\mathrm{T}_{\mathrm{g}}$ is an expected phenomenon due to the plasticizing effect of star PCL arms having very low $T_{g}(10,30)$. The incorporation of PDI to PLA/SP blends did not significantly affect the $T_{g}$ values of $80 / 20$ blend, but it caused an increase of $2-3{ }^{\circ} \mathrm{C}$ in 95/5 blends due to the formation of PLA-Co-SPs structures $(19,25)$. The pure PLA has a high melting temperature $\left(\mathrm{T}_{\mathrm{m}}\right)$ around $149.8{ }^{\circ} \mathrm{C}$ (31). There is an increment in the $T_{m}$ values of neat PLA with increasing PCL content.

It is observed that the crystallization temperature $\left(T_{c}\right)$ of PLA is also influenced by the incorporation of SPs, and there an increase with an increase of PCL ratio consistent with the literature (30). The addition of PDI caused an increase in $T_{c}$ when compared to the blends only PLA/SP in any of the blend ratios.
The degree of crystallinity $\left(X_{c}\right)$ for all the blends was calculated from the equation in the following form:

$$
\% X_{c}=\frac{\Delta H_{m}-\Delta H_{c}}{\Delta H^{*}{ }_{m} \phi}
$$

where $\Delta H_{m}$ value shows the melting enthalpy of samples $(\mathrm{J} / \mathrm{g}), \Delta H_{C}$ value shows crystallization enthalpy $(\mathrm{J} / \mathrm{g})$ and $\Delta H_{m}^{*}$ value is the standard melting enthalpy of pure PLA $(93.1 \mathrm{~J} / \mathrm{g}) . \varphi$ is the weight fraction of PLA in the blends. In general, the crystallinity values of the blends are below $13 \%$. Pure PLA has a crystalline value of $0.2 \%$, indicating that the crystals formed during cold crystallization. The addition of SP polymers results in a significant increase in the crystallinity of PLA. Similarly, PLA crystallinity causes an increase with the addition of PDI, but this increase is lower than pure blends. Also, there is a reduction in the crystallinity values with the increment of PCL concentration in the blend (7). 
Table 2: The results of DSC analysis PLA/SP and PLA/PDI/SP blends at 95/5 and 80/20.

\begin{tabular}{|c|c|c|c|c|c|}
\hline & Blends & $\left(\begin{array}{c}\mathbf{T}_{\mathbf{g}} \\
\left({ }^{\circ} \mathbf{C}\right)\end{array}\right.$ & $\begin{array}{c}T_{c} \\
\left({ }^{\circ} \mathbf{C}\right)\end{array}$ & $\begin{array}{c}T_{m} \\
\left({ }^{\circ} \mathbf{C}\right)\end{array}$ & $\begin{array}{c}X_{c} \\
(\%)\end{array}$ \\
\hline & PLA & 55.4 & 117.4 & 149.8 & 0.2 \\
\hline & PLA/PDI & 54.8 & 113.7 & 152.1 & 1.6 \\
\hline & PLA/SP10 & 52.9 & 99.01 & 153.9 & 12.6 \\
\hline & PLA/SP20 & 52.9 & 98.05 & 154.6 & 12.6 \\
\hline & PLA/SP30 & 52.8 & 98.4 & 154.8 & 12.3 \\
\hline $05 / 5$ & PLA/SP50 & 52.4 & 98.7 & 154.8 & 12.1 \\
\hline בונדב & PLA/PDI/SP10 & 55.3 & 110.4 & 155.9 & 6.9 \\
\hline & PLA/PDI/SP20 & 54.5 & 103.4 & 155.5 & 6.4 \\
\hline & PLA/PDI/SP30 & 54.5 & 102.1 & 155.6 & 6.4 \\
\hline & PLA/PDI/SP50 & 54.1 & 101.1 & 156.6 & 6.1 \\
\hline & PLA/SP10 & 47.3 & 108.5 & 154.5 & 5.1 \\
\hline & PLA/SP20 & 47.8 & 106.7 & 154.9 & 4.8 \\
\hline & PLA/SP30 & 48.8 & 106.8 & 154.1 & 4.7 \\
\hline $80 / 20$ & PLA/SP50 & 48.8 & 106.8 & 154.5 & 4.2 \\
\hline $80 /<0$ & PLA/PDI/SP10 & 48.1 & 110.7 & 155.1 & 5.5 \\
\hline & PLA/PDI/SP20 & 48.4 & 110.5 & 154.2 & 4.9 \\
\hline & PLA/PDI/SP30 & 49.1 & 110.3 & 154.7 & 3.7 \\
\hline & PLA/PDI/SP50 & 49.03 & 110.1 & 155.1 & 2.4 \\
\hline
\end{tabular}

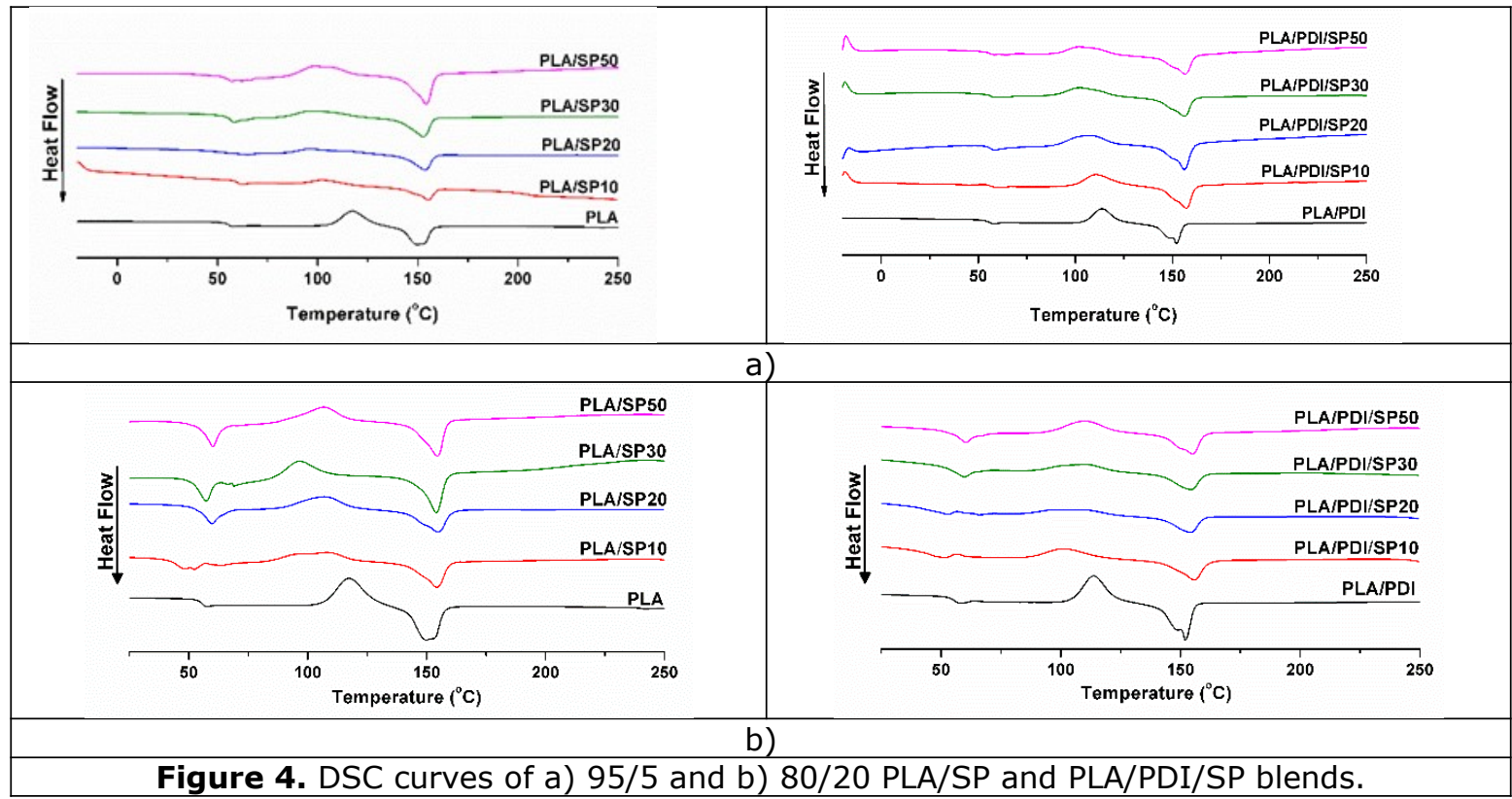

TGA helped investigate the thermal stability of PLA/ SP, and PLA/PDI/SP blends in Figure 5 and the values of $T_{5}, T_{10}$, and $T_{50}$ (the temperatures at which a weight loss of 5,10 , and $50 \%$ occurred), $T_{\text {onset }}$ (the onset decomposition temperature), $\mathrm{T}_{\max }$ (the maximum decomposition temperature), and the char yield of these blends were given in Table 3. PLA has the highest thermal stability, while a decrease is seen with the addition of SP polymers to PLA matrix due to the structural differences of the PLA and PCL polymers and the low thermal stability of PCL. PDI also has a decreasing effect on thermal properties, as seen in Table 3. The char yield values increased with the increment in the PCL amount in the blends. 
Table 3: The results of the TGA analysis of PLA/SP and PLA/PDI/SP blends at 95/5 and 80/20.

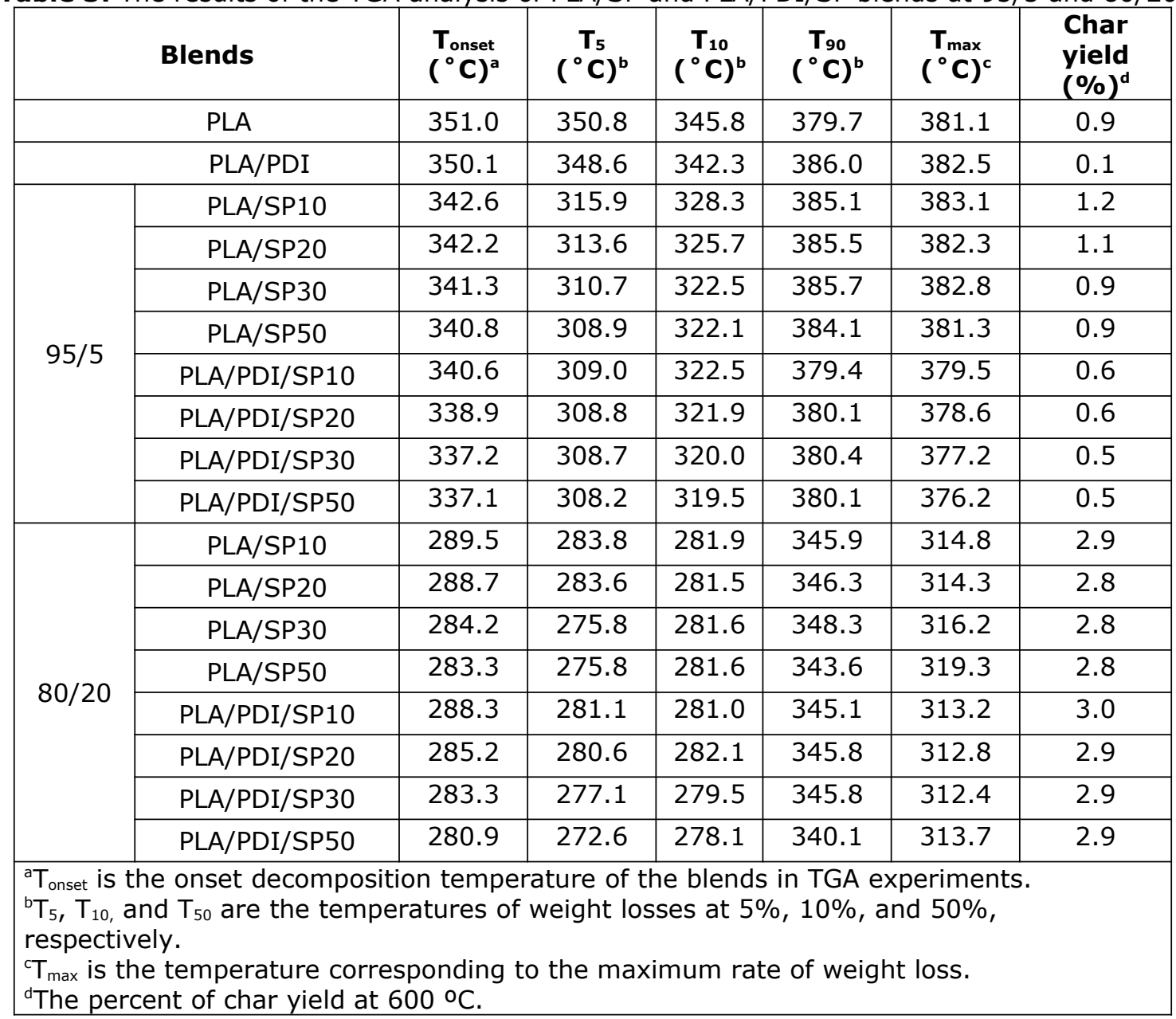

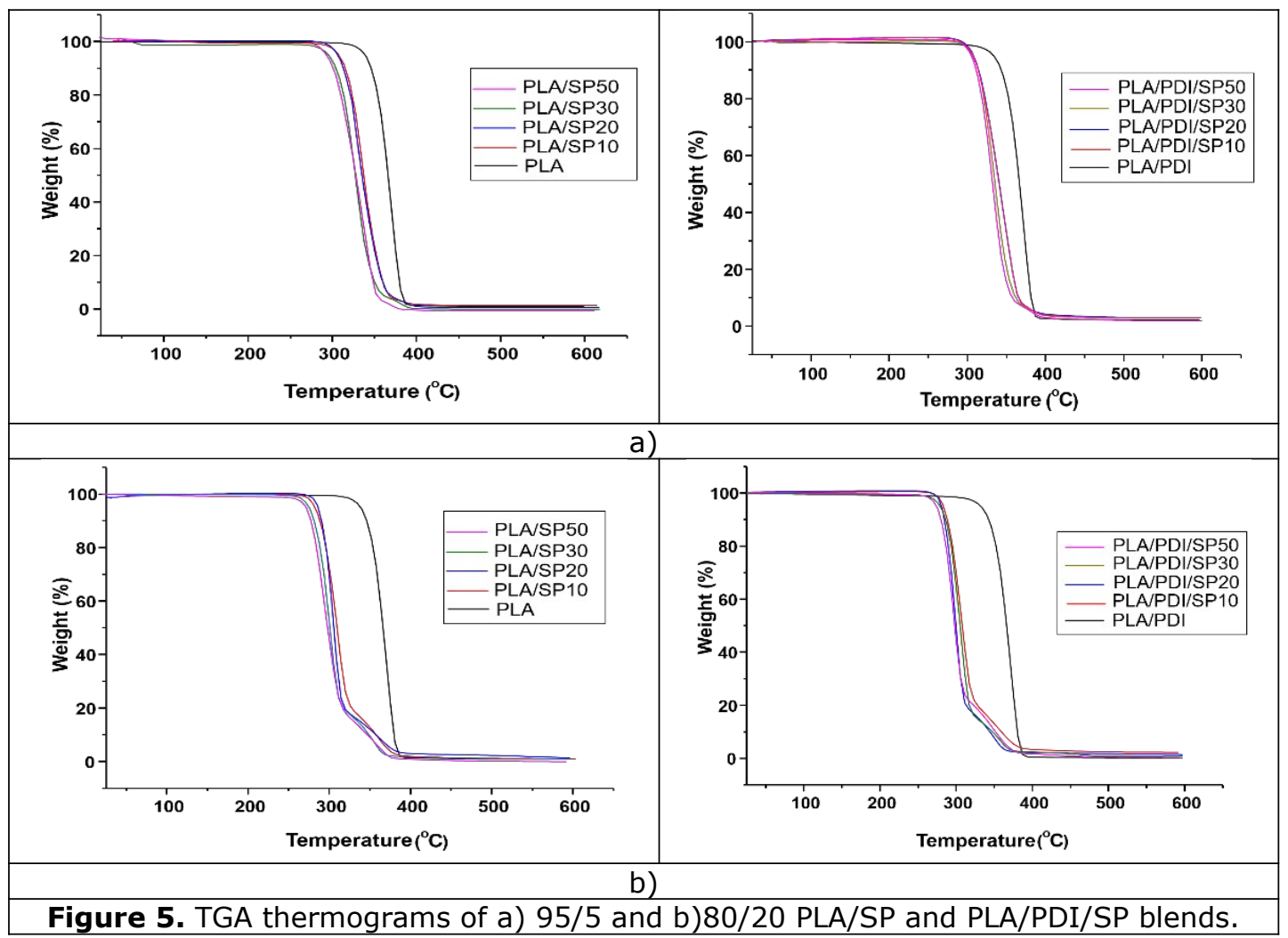




\section{Morphology}

The compatibility and the blending ratios of the blends are two critical parameters that affect the interfacial adhesion and the phase dispersions, as well as the size, uniformity, and distributions of the dispersed phase in the continual phase. Correlatively, the toughness and mechanical properties of the blends are precisely influenced. Figure 6 shows the SEM photos of fracture surfaces of PLA/SP and PLA/PDI/SP blends at 95/5 and 80/20 ratios at 5000x magnification.

Neat PLA is a brittle polymer showing large cracks on the fracture surface $(10,19)$. PLA matrix is a continuous phase, and PDI and the added SP polymers are dispersed phase in this multicomponent blend system. In 95/5 blends, in which PLA is a rich component, the surfaces prepared with SPs having 10, 20 and 30 arm length have large cracks as seen Figure 6, however, these larger cracks disappear with SP50, and globular PCL structures appear in the PLA matrix this is due to longer PCL arms penetrate PLA matrix easily with its star shape structure. Besides, the globular PCL structure appears with SP10 at $80 / 20$ blends. The SP polymers act as stress concentrators and cause a decrement of tensile modulus (Figure 2a) (7). The distribution of SP in PLA is homogeneous, and this shows that SP is better miscible than linear PCL polymers $(4,19)$. Two distinct phases cannot be seen with the addition of PDI, so it enhances the immiscibility, and the SEM results are coherent with the formation of a PLA-CO-SP due to the reactive compatibilization.

\section{CONCLUSION}

$\mathrm{A}_{8}$-type eight-armed POSS cored star-shaped PCL polymers (SP) with different arm lengths (SP10, SP20, SP30, and SP50) were synthesized and meltblended with commercial PLA at different ratios as $95 / 5$ and $80 / 20$ to examine the effects on the mechanical, morphological behavior and toughness of PLA. The results are compared with the results of a previous study that was at a $90 / 10$ ratio (19). It was reported that using a star-shaped polymer rather than linear ones enhanced morphological and mechanical properties. The incorporation of SP polymers into the PLA matrix decreased the tensile modulus and increased the EAB values. The impact properties of the blends were also considerably improved. PLA/PDI/SP20 blends with a blending ratio of $90 / 10$ have the maximum $E A B$ and the impact strength values thanks to chain extension reactions between PDI and SP20. Here, it is also showed that when the blending ratio was increased, it improves the morphology, and there are no large cracks that are seen on pure PLA surface. Also, there are no two distinct phases with the addition of PDI due to the chain extension reactions. It can be concluded that the fragile nature of pure PLA turned to ductile by blending via SP polymers, and using SP polymers rather than linear ones is more successful in enhancing mechanical properties of neat PLA. Hence, the application field of PLA was broadened by blending with SP biopolymers, and these blends can be utilized for various daily and industrial applications such as food packaging, disposable products, biomedical, etc. 


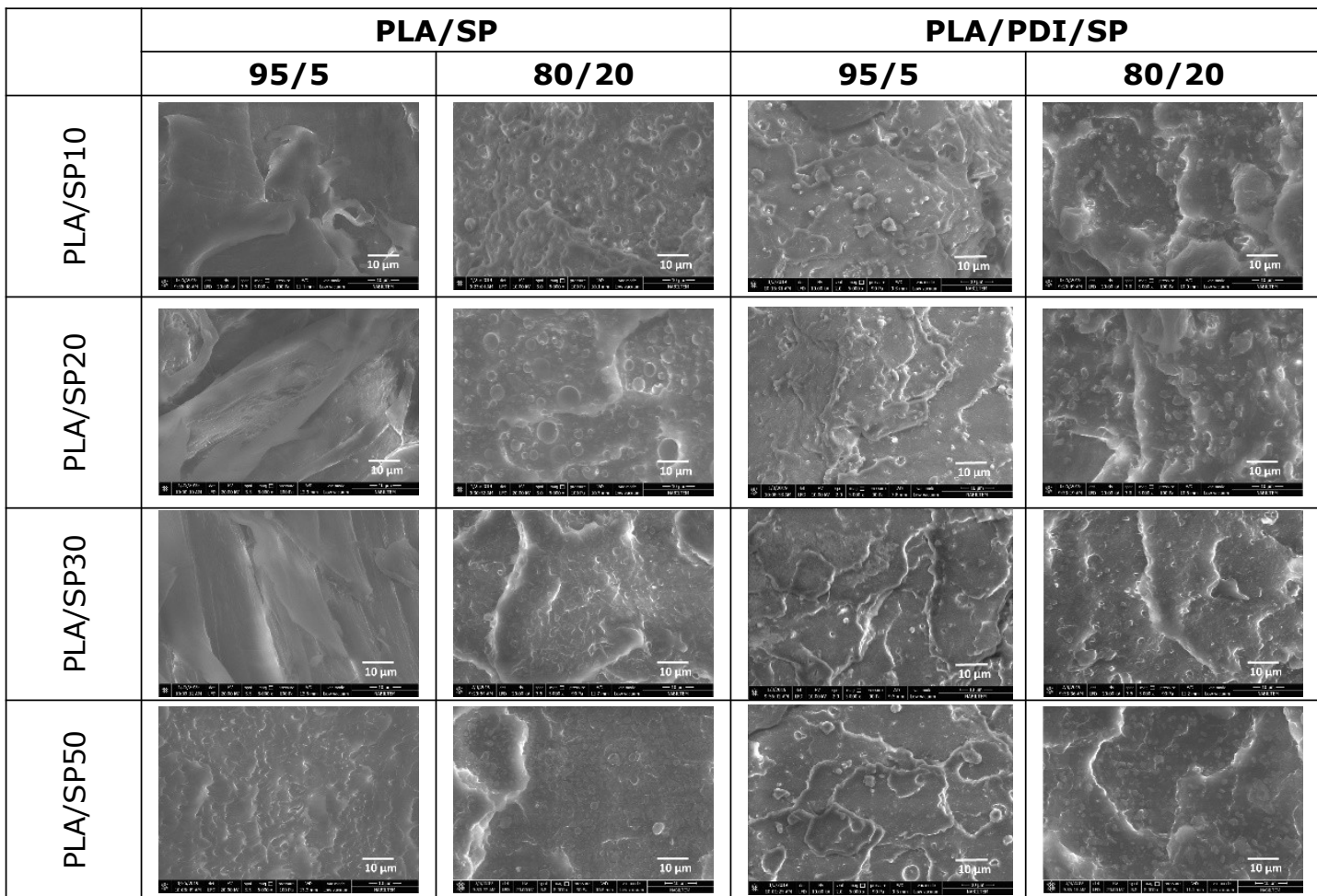

Figure 6. SEM images of $95 / 5$ and $80 / 20$ PLA/SP and PLA/PDI/SP blends at 5000X magnifications.

\section{ACKNOWLEDGEMENT}

This work was supported by The Scientific and Technical Research Council of Turkey (TUBITAK, Project No. 117M271).

\section{REFERENCES}

1. Urquijo J, Guerrica-Echevarría G, Eguiazábal JI. Melt processed PLA/PCL blends: Effect of processing method on phase structure, morphology, and mechanical properties. Journal of Applied Polymer Science. 2015;132(41).

2. López-Rodríguez $\mathrm{N}$, López-Arraiza $\mathrm{A}$, Meaurio E, Sarasua JR. Crystallization, morphology, and mechanical behavior of polylactide/poly $(\varepsilon$ caprolactone) blends. Polymer Engineering \& Science. 2006;46(9):1299-308.

3. Deokar MD, Idage SB, Idage BB, Sivaram S. Synthesis and characterization of well-defined random and block copolymers of $\varepsilon$-caprolactone with l-lactide as an additive for toughening polylactide: Influence of the molecular architecture. Journal of Applied Polymer Science. 2016;133(14).

4. Broz ME, VanderHart DL, Washburn NR. Structure and mechanical properties of $\operatorname{poly}(d, I-$ lactic acid)/poly( $\varepsilon$-caprolactone) blends. Biomaterials. 2003 2003/10/01/;24(23):4181-90.

5. Simões $C L$, Viana JC, Cunha AM. Mechanical properties of poly( $\varepsilon$-caprolactone) and poly(lactic acid) blends. Journal of Applied Polymer Science. 2009;112(1):345-52.

6. Rao RU, Suman KNS, Rao VVSK, Bhanukıran K. Study of rheological and mechanical properties of biodegradable polylactide and polycaprolactone blends. International Journal of Engineering Science and Technology. 2011:6259-65.

7. Matta AK, Rao RU, Suman KNS, Rambabu V. Preparation and Characterization of Biodegradable PLA/PCL Polymeric Blends. Procedia Materials Science. 2014 2014/01/01/;6:1266-70.

8. Hiljanen-Vainio M, Karjalainen T, Seppälä J. Biodegradable lactone copolymers. I. Characterization and mechanical behavior of $\varepsilon$ caprolactone and lactide copolymers. Journal of Applied Polymer Science. 1996;59(8):1281-8.

9. Li H, Qiao T, Song $P$, Guo $H$, Song $X$, Zhang $B$, et al. Star-shaped PCL/PLLA blended fiber membrane via electrospinning. Journal of Biomaterials Science, Polymer Edition. 2015 2015/05/03;26(7):420-32.

10. Qin $Y$, Liu S, Zhang $Y$, Yuan M, Li H, Yuan M. Effect of poly( $\varepsilon$-caprolactone-co-I-lactide) on thermal and functional properties of poly(I-lactide). International Journal of Biological Macromolecules. 2014 2014/09/01/;70:327-33.

11. Liu Z, Hu D, Huang L, Li W, Tian J, Lu L, et al. Simultaneous improvement in toughness, 
strength and biocompatibility of poly(lactic acid) with polyhedral oligomeric silsesquioxane. Chemical Engineering Journal. 2018 2018/08/15/;346:64961.

12. Pan R, Shanks R, He $Y$, Su Y. Molecular shape conversion of POSS-(PLLA) $X$ with various arm lengths and its effect on the compatibility of PLLA/POSS-(PLLA) $x$ as a nanofiller blended into PLLA matrix: From spiky ball to panel-like. Computational Materials Science. 2019 2019/06/15/;164:1-7.

13. Kodal $M$, Sirin $H$, Ozkoc $G$. Effects of reactive and nonreactive POSS types on the mechanical, thermal, and morphological properties of plasticized poly(lactic acid). Polymer Engineering \& Science. 2014;54(2):264-75.

14. Dilek T, Humeyra S, Guralp O. Effects of POSS particles on the mechanical, thermal, and morphological properties of PLA and Plasticised PLA. Journal of Applied Polymer Science. 2011;121(2):1067-75.

15. Pan $\mathrm{H}, \mathrm{Yu}$ J, Qiu Z. Crystallization and morphology studies of biodegradable poly $(\epsilon-$ caprolactone)/polyhedral oligomeric silsesquioxanes nanocomposites. Polymer Engineering \& Science. 2011;51(11):2159-65.

16. Monticelli O, Calabrese M, Gardella L, Fina A, Gioffredi E. Silsesquioxanes: Novel compatibilizing agents for tuning the microstructure and properties of PLA/PCL immiscible blends. European Polymer Journal. 2014 2014/09/01/;58:69-78.

17. Wang $W$, Fei $M$, Jie $X$, Wang $P$, Cao $H$, Yu J. Synthesis and characterization of star-shaped block copolymers with polyhedral oligomeric silsesquioxane (POSS)core via ATRP. Polymer Bulletin. 2010 December 01;65(9):863-72.

18. Lee KS, Chang YW. Thermal and mechanical properties of poly ( $\varepsilon$-caprolactone)/polyhedral oligomeric silsesquioxane nanocomposites. Polymer International. 2013;62(1):64-70.

19. Dandan Doganci M, Aynali F, Doganci $E$, Ozkoc G. Mechanical, thermal and morphological properties of poly(lactic acid) by using star-shaped poly( $\varepsilon$-caprolactone) with POSS core. European Polymer Journal. 2019 2019/12/01/;121:109316.

20. Sun Y, He C. Biodegradable "Core-Shell" Rubber Nanoparticles and Their Toughening of Poly(lactides). Macromolecules. 2013 2013/12/23;46(24):9625-33.

21. Aloorkar N, Kulkarni A, Patil R, Ingale D. Star polymers: an overview. Int J Pharm Sci Nanotech. 2012;5:1675-84.
22. Turan D, Sirin H, Ozkoc G. Effects of POSS particles on the mechanical, thermal, and morphological properties of PLA and Plasticised PLA. Journal of Applied Polymer Science. 2011;121(2):1067-75.

23. Romero-Guzmán ME, Romo-Uribe A, ZárateHernández BM, Cruz-Silva R. Viscoelastic properties of POSS-styrene nanocomposite blended with polystyrene. Rheologica Acta. 2009 July $01 ; 48(6): 641-52$.

24. Meredith JC, Amis EJ. LCST phase separation in biodegradable polymer blends: poly(D,L-lactide) and poly( $\epsilon$-caprolactone). Macromolecular Chemistry and Physics. 2000;201(6):733-9.

25. Dogan SK, Reyes EA, Rastogi S, Ozkoc G. Reactive compatibilization of PLA/TPU blends with a diisocyanate. Journal of Applied Polymer Science. $2014 ; 131(10)$

26. Kilic NT, Can BN, Kodal M, Ozkoc G. Compatibilization of PLA/PBAT blends by using Epoxy-POSS. Journal of Applied Polymer Science. 2019;136(12):47217.

27. Zhao X, Hu H, Wang X, Yu X, Zhou W, Peng S. Super tough poly (lactic acid) blends: a comprehensive review. RSC Advances. 2020;10(22):13316-68.

28. Fortelny I, Ujčić A, Fambri L, Slouf M. Phase structure, compatibility and toughness of PLA/PCL blends: a review. Frontiers in Materials. 2019;6:206.

29. Zhao H, Zhao G. Mechanical and thermal properties of conventional and microcellular injection molded poly (lactic acid)/poly $(\varepsilon-$ caprolactone) blends. Journal of the Mechanical Behavior of Biomedical Materials. 2016 2016/01/01/;53:59-67.

30. Yeh J-T, Wu C-J, Tsou C-H, Chai W-L, Chow J-D, Huang $C-Y$, et al. Study on the Crystallization, Miscibility, Morphology, Properties of Poly(lactic acid)/Poly( $\varepsilon$-caprolactone) Blends. Polymer-Plastics Technology and Engineering. 2009 2009/05/18;48(6):571-8.

31. Garlotta D. A Literature Review of Poly(Lactic Acid). Journal of Polymers and the Environment. 2001 April 01;9(2):63-84.

32. Migliaresi C, Cohn D, De Lollis A, Fambri L. Dynamic mechanical and calorimetric analysis of compression-molded PLLA of different molecular weights: Effect of thermal treatments. Journal of Applied Polymer Science. 1991;43(1):83-95. 
DANDAN DOĞANCI M. JOTCSA. 2020; 7(3): 649-660.

33. Lim LT, Auras R, Rubino M. Processing technologies for poly(lactic acid). Progress in Polymer Science. 2008 2008/08/01/;33(8):820-52. 